\title{
Surgical technique: coupling of intrastromal corneal ring segments for ectatic corneal disorders in eye bank corneas
}

This article was published in the following Dove Press journal:

Clinical Ophthalmology

7 October 2011

Number of times this article has been viewed

\author{
Majid Moshirfar' \\ Maylon Hsu' \\ Yousuf M Khalifa ${ }^{2}$ \\ 'Moran Eye Center, Salt Lake City, \\ UT, ${ }^{2}$ Flaum Eye Institute, Rochester, \\ NY, USA
}

\begin{abstract}
The management of corneal ectasia is evolving, with intrastromal corneal ring segments playing an important role in delaying or eliminating the need for penetrating keratoplasty. This paper describes a modification in the implantation technique of intrastromal corneal ring segments that allows for coupling of the two segments with suture, affording more structural support.
\end{abstract}

Keywords: intrastromal corneal ring segments, Intacs, keratonconus, corneal ectasia, keratoectasia

\section{Introduction}

Originally introduced as an additive refractive surgical procedure for low to moderate myopia, ${ }^{1}$ intrastromal corneal ring segments (ICRS) have evolved into an important tool in the management of corneal ectatic disorders ${ }^{2}$ including keratoconus, ${ }^{3}$ pellucid marginal degeneration, ${ }^{4}$ and post laser-assisted in situ keratomileusis (LASIK) ectasia. ${ }^{5}$ Currently, the only US Food and Drug Administration-approved ICRS in the USA is Intacs (Addition Technology, Inc, Sunnyvale, CA).

ICRS flatten the cornea by means of a spacer effect in which the central arc length of the cornea is decreased..$^{2}$ ICRS have been shown to provide refractive stability over time and slow down the progression of ectasia. ${ }^{5}$ The authors here propose a coupling technique to provide further posterior cornea stress relief for ectatic disease. The suture-coupled Intacs segments create a $360^{\circ}$ ring complex (Figure 1) that is inserted into standard femtosecond laser-created intrastromal channels.

\section{Surgical technique}

Two ICRS were positioned on the storage tray to simulate their position in the cornea (Figure 2A). While maintaining this configuration, a 9-0 nylon suture was passed through the superior islet of the first segment (Figure 2B), then through the superior islet of the second segment (Figure 2C). Care was taken to ensure the ICRS maintained their configuration and that the suture did not cross from the superior aspect of one segment to the inferior aspect of the other islet. An 18-gauge needle was then placed between the two segments in the middle of the loop created by the 9-0 nylon, and the suture was tied with a standard knot (Figure 2D).

A human donor globe was obtained from the Utah Lions Eye Bank (Salt Lake City, UT). The center of the cornea was marked with a Sinskey hook on the epithelial surface. Standard technique with femtosecond laser (IntraLase ${ }^{\mathrm{TM}}$; Abbott Medical Optics, 


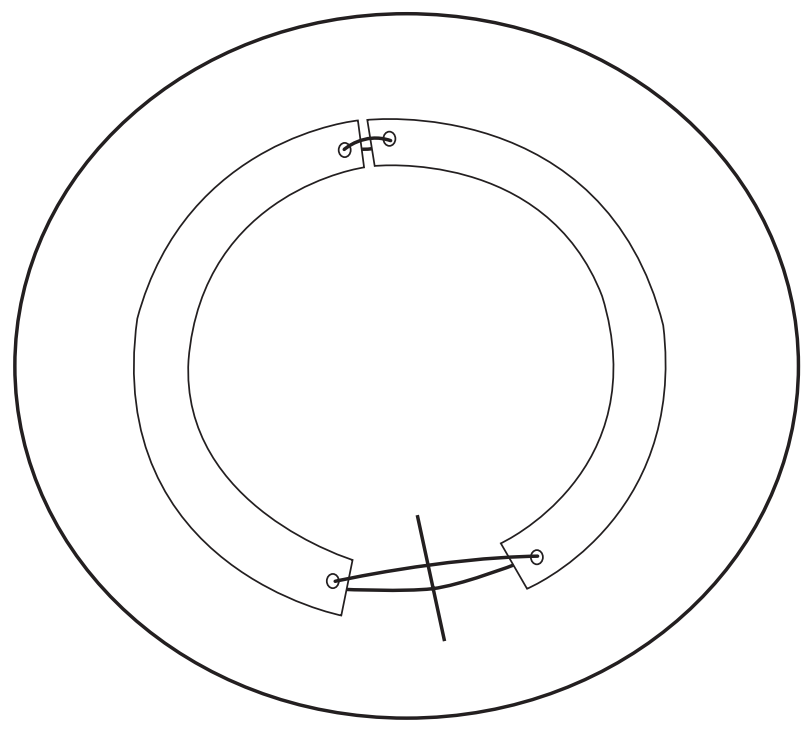

Figure I Schematic of the Intacs segments coupled with suture at both ends. The radial corneal incision is depicted inferiorly prior to suture closure.

Santa Ana, CA) was used to fashion the channels at $70 \%$ depth, $6.8 \mathrm{~mm}$ internal diameter, and $7.8 \mathrm{~mm}$ external diameter. The symmetric glide was used to evaluate the pockets.

The first segment was inserted completely (Figure 3A) with the loop of 9-0 nylon attached to the second segment, causing it to trail. The second segment was passed through the same side of the incision and used to push the first segment through the channel. The needle of a double armed 9-0 nylon suture was then passed through the second segment inferior islet (Figure 3B) from the posterior surface of the islet. The second segment inferior islet is then engaged with
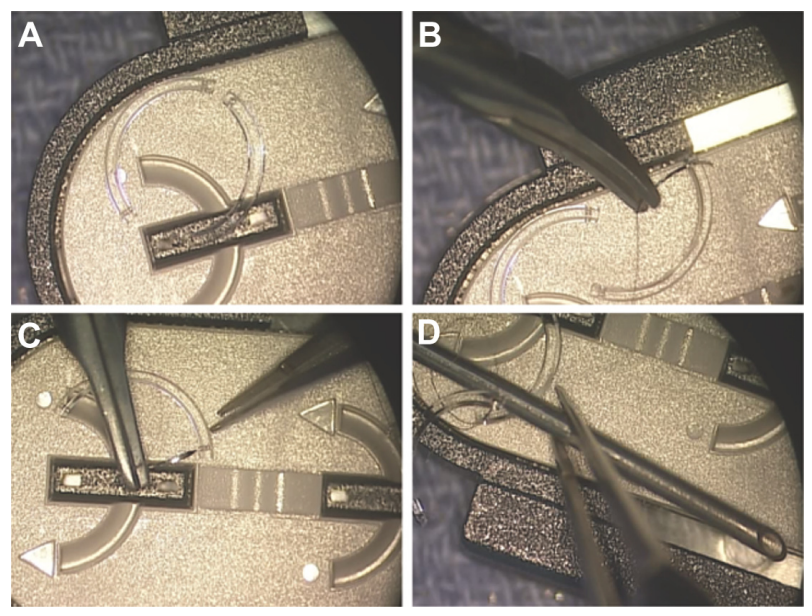

Figure 2 Two intrastromal corneal ring segments were positioned on the storage tray to simulate their position in the cornea (A). 9-0 nylon suture was passed through the superior islet of the first segment (B) then through the superior segment of the second segment (C). An 18-gauge needle was then placed between the two segments in the middle of the loop created by the 9-0 nylon, and the suture was tied with a standard knot (D). a Sinskey hook and advanced (Figure 3C). By passing the Sinskey hook through the other side of the channel, the first segment inferior islet is engaged (Figure 3D), and the islet is pulled out of the wound (Figure 3E). The other arm of the 9-0 nylon is then passed through the posterior surface of the islet of the first segment carefully so as to not allow the suture to cross or twist (Figure 3E). The segments are then positioned to be equidistant from the incision (Figure 3F) and then a surgical knot is thrown with the desired tension (Figure 3G). The Intacs incision is then closed in usual fashion with a 10-0 nylon.

\section{Discussion}

The original intrastromal corneal segment design (Intrastromal Corneal Ring, KeraVision, Inc, Fremont, CA) was a $360^{\circ}$ ring composed of polymethylmethacrylate. ${ }^{1}$ This was reconfigured as two separate $150^{\circ}$ Intacs segments due to wound healing complications at the incision site directly overlying the ring and for improved ease of surgical insertion. ${ }^{1,6}$ ICRS were originally designed as an additive approach to treat myopia through reduction of the central arc length, which in effect flattens the cornea. The same premise has been applied to ectatic diseases such as keratoconus, pellucid marginal degeneration, and post-LASIK ectasia. ${ }^{2-5}$

In a study of keratoconus using confocal microscopy, Hollingsworth and Efron concluded that the clinical sign of Vogt's striae is indicative of collagen lamellae under stress. ${ }^{7}$ The authors have noted the same phenomenon on confocal microscopy of keratoconic corneas with stress lines intersecting at the center of the cone (Figure 4). The depth of these tension lines explains why ICRS segments work best when they are implanted deep within the stroma. The relief of the posterior lamellae may also explain why ICRS have been shown to slow progression of ectasia. ${ }^{5}$

By increasing both the thickness and arc length of ICRS, a greater degree of cornea flattening has been observed. ${ }^{8}$ Although not approved in the USA, newer modifications of ICRS have recently increased the arc length available. The use of single $210^{\circ}$ intrastromal corneal rings (Ferrara Intrastromal Corneal Ring [Ferrara Ophthalmics, Belo Horizonte, Brazil] and Kerarings [Mediphacos Ltd, Belo Horizonte, Brazil]) for keratoconus ${ }^{9}$ and pellucid marginal degeneration ${ }^{10}$ showed improved visual outcomes and corneal flattening, with less unpredictable astigmatic induction. In keratconous patients, a flexible intracorneal continuous ring (MyoRing ICCR, Dioptex GmbH, Linz, Austria) implanted into an intrastromal corneal pocket allowed for recentering of the ring postoperatively, to further adjust 

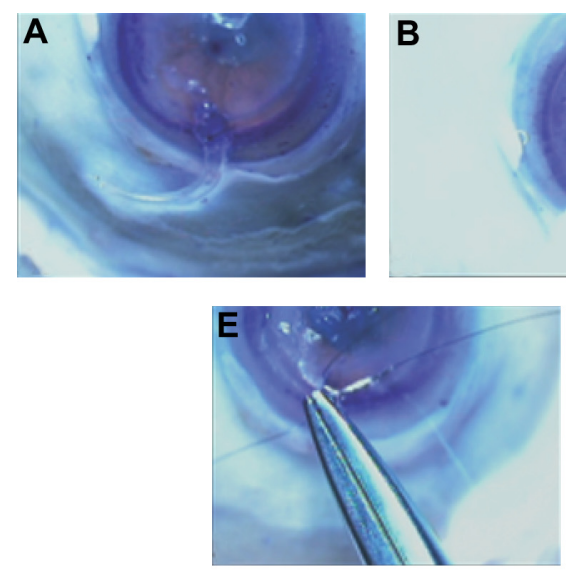
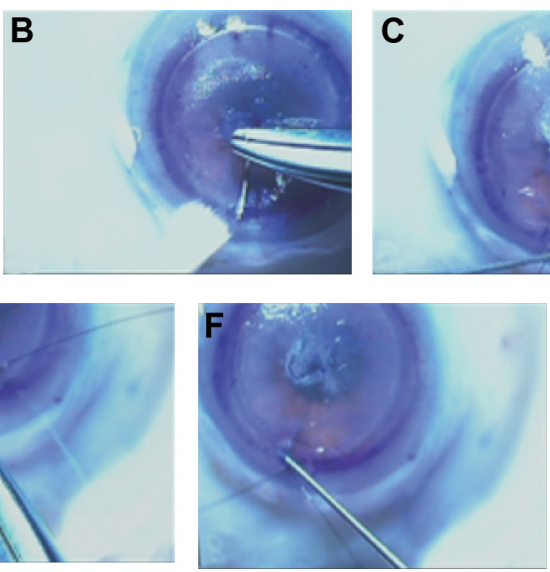
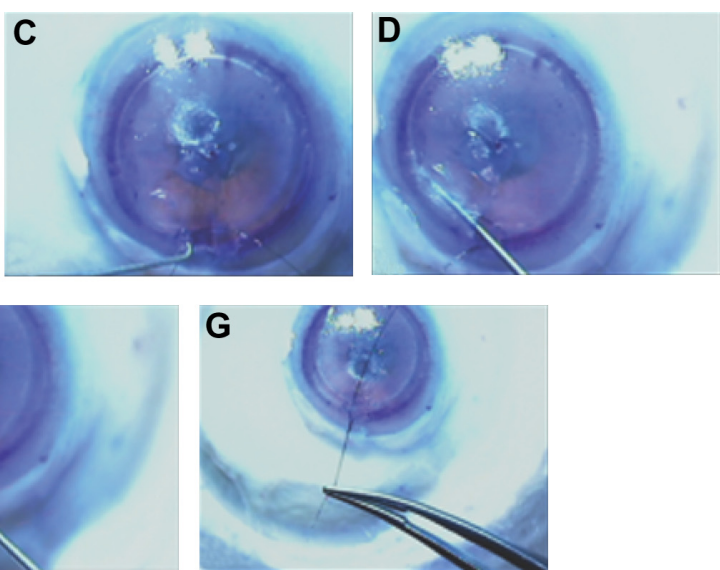

Figure 3 The first segment was inserted completely $(\mathbf{A})$. The second segment was passed through the same side of the incision and used to push the first segment through the channel (B). The needle of a double armed 9-0 nylon suture was then passed through the second segment inferior islet (B). The second segment inferior islet was then engaged with a Sinskey hook and advanced (C). By passing the Sinskey hook through the other side of the channel, the first segment inferior islet is engaged (D), and the islet is pulled out of the wound (E). The other arm of the 9-0 nylon is then passed through the posterior surface of the islet of the first segment with attention not to allow the suture to cross or twist (E). The segments are then positioned to be equidistant from the incision (F) and then a surgical knot is thrown with the desired tension (G).

refractive outcomes. ${ }^{11}$ No studies have directly compared outcomes of continuous rings with ring segments.

The described coupling technique is another option to not only cover an extended arc length but also create a "purse string" effect of enhanced structural support. This may provide further and more uniform reinforcement to help delay progressive ectasia and refractive changes. Several authors have reported success with asymmetric ring segments, especially in inferiorly displaced cones in which a thicker ICRS in placed inferiorly with a thinner ICRS placed superiorly. ${ }^{12,13}$ Such asymmetric ring segments could also be

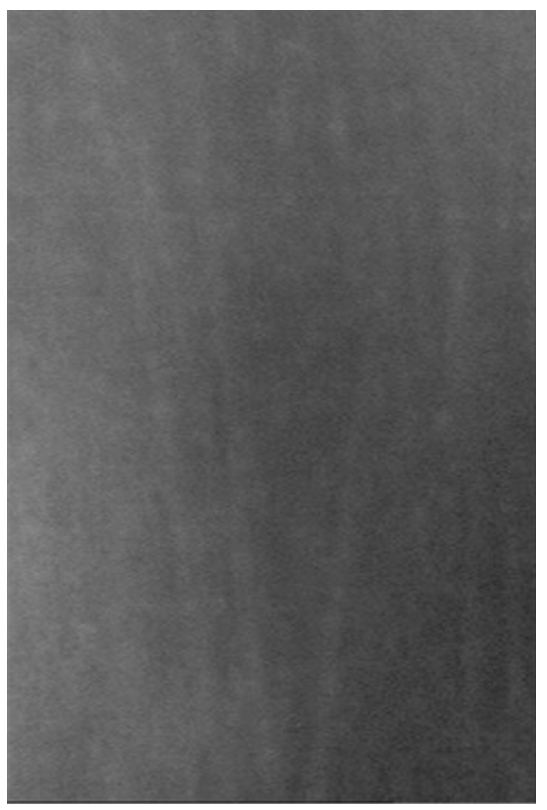

Figure 4 Confocal microscopy of keratoconus showing the deep stress lines in the posterior stroma. coupled with suture to enhance and prolong the desired effect. The suturing of the ring segments together can better secure the planned position of the ICRS, without the undesired effects of migration. This could also potentially decrease complications of extrusion.

Clinical studies are needed to validate the proposed enhancement of coupling Intacs segments. If explantation is needed, after removing the joining suture under the original radial incision site, the attached segments could be removed together through one side of the incision site. Possible complications include cheese wiring of the suture through the islets or suture loosening, which may reduce the coupling effect over time.

The management of corneal ectasia is evolving with multiple intermediate alternatives before penetrating keratoplasty. ICRS technology is readily available and the surgical technique is relatively uncomplicated. The modification proposed here does not add significantly to the complexity of the technique. Further studies evaluating the effect of ICRS coupling in the clinical setting are needed.

\section{Disclosure}

The authors report no conflicts of interest in this work.

\section{References}

1. Burris TE. Intrastomal corneal ring technology: results and indications Curr Opinion Ophthalmol. 1998;9(4):9-14.

2. Pinero DP, Alio JL. Intracorneal ring segments in ectatic corneal disease - a review. Clin Experiment Ophthalmol. 2010;38:154-167.

3. Dauwe C, Touboul D, Roberts CJ, et al. Biomechanical and morphological corneal response to placement of intrastromal corneal ring segments for keratoconus. J Cataract Refract Surg. 2009;35(10):1761-1767.

4. Piñero DP, Alio JL, Morbelli H, et al. Refractive and corneal aberrometric changes after intracorneal ring implantation in corneas with pellucid marginal degeneration. Ophthalmology. 2009;116(9):1656-1664. 
5. Kymionis GD, Tsiklis NS, Pallikaris AI, et al. Long-term follow-up of Intacs for post-LASIK corneal ectasia. Ophthalmology. 2006;113(11): 1909-1917.

6. Schwartz AR, Tinio BO, Esmail F, Babayan A, Naikoo HN, Asbell PA. Ten-year follow-up of 360 degrees intrastromal corneal rings for myopia. J Refract Surg. 2006;22(9):878-883.

7. Hollingsworth JG, Efron N. Observations of banding patterns (Vogt striae) in keratoconus: a confocal microscopy study. Cornea. 2005;24: $162-166$.

8. Schanzlin DJ. Studies of intrastromal corneal ring segments for the correction of low to moderate myopic refractive errors. Trans Am Ophthalmol Soc. 1999;97:815-890.

9. Ferrara P, Torquetti L. Clinical outcomes after implantation of a new intrastromal corneal ring with a 210-degree arc length. J Cataract Refract Surg. 2009;35(9):1604-1608.
10. Kubaloglu A, Sari ES, Cinar Y, et al. A single 210-degree arc length intrastromal corneal ring implantation for the management of pellucid marginal corneal degeneration. Am J Ophthalmol. 2010;150(2): 185-192.

11. Daxer A, Mahmoud H, Venkateswaran RS. Intracorneal continuous ring implantation for keratoconus: One-year follow-up. J Cataract Refract Surg. 2010;36(8):1296-1302.

12. Boxer Wachler BS, Christie JP, Chandra NS, Chou B, Korn T, Nepomuceno R. Intacs for keratoconus. Ophthalmology. 2003;110(5): 1031-1040.

13. Rabinowitz YS. INTACS for Keratoconus. Int Ophthalmol Clin. 2010; 50(3):63-76.
Clinical Ophthalmology

\section{Publish your work in this journal}

Clinical Ophthalmology is an international, peer-reviewed journal covering all subspecialties within ophthalmology. Key topics include: Optometry; Visual science; Pharmacology and drug therapy in eye diseases; Basic Sciences; Primary and Secondary eye care; Patient Safety and Quality of Care Improvements. This journal is indexed on

\section{Dovepress}

PubMed Central and CAS, and is the official journal of The Society of Clinical Ophthalmology (SCO). The manuscript management system is completely online and includes a very quick and fair peer-review system, which is all easy to use. Visit http://www.dovepress.com/ testimonials.php to read real quotes from published authors. 